УДК: $631.438 .2 ; 544.034 .24 ; 532.5-1 /-9$

\title{
ИСПОЛЬЗОВАНИЕ ЭЛЕКТРООСМОТИЧЕСКОГО ЭФФЕКТА ДЛЯ ОСУШЕНИЯ БАРЬЕРОВ БЕЗОПАСНОСТИ ПРИ ВЫВОДЕ ИЗ ЭКСПЛУАТАЦИИ ЯДЕРНО- И РАДИАЦИОННО ОПАСНЫХ ОБЪЕКТОВ
}

\section{Антоненко Михаил Викторович',} antonenkomv26@mail.ru

\author{
Леонов Алексей Вячеславович', \\ leonovav26@mail.ru
} Беспала Евгений Владимирович',
bespala_evgeny@mail.ru

\author{
Чубреев Дмитрий Олегович', \\ d.chubreev@gmail.com
}

\author{
Беспала Юлия Рашидовна', \\ yrbespala@gmail.com \\ 1 Федеральное государственное унитарное предприятие «Горно-химический комбинат», \\ Россия, 662972, Красноярский край, г. Железногорск, ул. Ленина, 53.
}

\begin{abstract}
Актуальность исследования обусловлена необходимостью разработки новых инновационных неразрушающих технологий восстановления целостности и осушения барьеров безопасности на основе смеси природных глин, создаваемых при выводе из эксплуатации ядерно- и радиационно опасных объектов.

Цель исследования: выявление физико-химических особенностей глиносодержащего барьерного материала, используемого при создании дополнительных барьеров безопасности при выводе из эксплуатации ядерно- и радиационно опасных объектов, а также разработка и апробация способа осушения таких барьеров электроосмотическим методом.

Методы исследования: аналитическое и экспериментальное исследование электроосмотического эффекта, возникающего при осушении барьеров безопасности на основе смеси природных глин.

Результаты. Показано, что используемые при выводе из эксплуатации ядерно- и радиационно опасных объектов барьерные материалы на основе бентонита способны сохранять свои уникальные противофильтрационные и противомиграционные свойства на протяжении всего времени потенциальной опасности объекта. Акцентировано внимание на то, что такие барьеры безопасности могут быть подвержены внешнему негативному воздействию (техногенному или природному), что приводит к частичному ухудшению их противофильтрационных и противомиграционных свойств. Доказано, что для восстановления целостности и работоспособности глиносодержащих барьеров безопасности целесообразно использовать методы, не приводящие к ещё большей деградации барьерного материала. Для этих целей предложено использовать электроосмотический метод, основанный на капиллярном движении влаги в электрическом поле. Указанный электроосмотический метод восстановления глиносодержащих барьеров безопасности позволяет концентрировать влагу возле одного из электродов, тем самым осушать прилегающую область глины. Показано, что эффективнее всего удаляется раствор, имитирующий грунтовые воды из пункта глубинного захоронения радиоактивных отходов. При напряжении 31,8 В и расстоянии между электродами 40 мм линейная скорость движения влаги составляет 2,5 мм/мин. Это позволяет полностью осушить глиносодержащий барьер безопасности, обводненный 70 мл раствора, в течение 7-8 часов. Выявлено, что в результате рекомбинации диссоциированных ионов солей и воды на электродах происходит прилипание, спекание и омоноличивание барьерного материала в приэлектродной области. Это позволяет удалить деградированный барьерный материал вместе с электродом. Установлено, что в области концентрирования влаги вблизи катода происходят химические реакции, результатом которых является выделение газообразных продуктов, что позволяет удалять жидкость без использования специальных средств в непрерывном режиме.
\end{abstract}

\section{Ключевые слова:}

Ядерно- и радиационно опасный объект, барьерный материал, природные глины,

вывод из эксплуатации, электроосмос, миграция, радионуклид.

\section{Введение}

Частью Федеральных целевых программ ФЦП ЯРБ-1 «Обеспечение ядерной и радиационной безопасности на 2008 год и на период до 2015 года» и ФЦП ЯРБ-2 «Обеспечение ядерной и радиационной безопасности на 2016-2020 годы и на период до 2030 года», принятых Правительством Российской Федерации, является вывод из эксплуатации (ВЭ) ядерно- и радиационно опасных объектов (ЯР00) [1]. К таким объектам, помимо всего про- чего, относятся: промышленные уран-графитовые реакторы (ПУГР) и приреакторные хранилища твёрдых (ТРО) и жидких (ЖРО) радиоактивных отходов $[2,3]$. $K$ настоящему времени на территории РФ расположено 13 ПУГР, из них 11 ПУГР находятся в стадии ВЭ (А, АИ, АВ-1,2,3, И-1, АДЭ-1,3,4,5, АД) [4].

В соответствии с концепцией «Вывод из эксплуатации ядерных установок, радиационных источников и пунктов хранения» вывод из эксплуа- 
тации ЯРОО может проводиться по вариантам «Ликвидация» и «Захоронение на месте». ВЭ по варианту «Захоронение на месте» осуществляется путём надёжной изоляции РАО на территории размещения ПУГР, обеспечивающей радиационную безопасность персонала, населения и окружающей среды на весь период потенциальной опасности РАО. При реализации данной концепции непосредственно для основных конструкций реакторных установок (графитовая кладка, несущие металлоконструкции, биологическая защита), относящихся к категории особых РАО и не подлежащих демонтажу и удалению, выполнение указанных требований возможно только при условии создания дополнительных барьеров безопасности, обеспечивающих надежную изоляцию радионуклидов, содержащихся в материалах и конструкциях захораниваемых реакторных установок.

Искусственные барьеры безопасности на основе природных глин создаются, как правило, с помощью специально разработанной технологии бесполостного заполнения [5]. Такой подход был использован при ВЭ ПУГР ЭИ-2 (г. Северск, Томская область) [6] и АД (г. Железногорск, Красноярский край) [7]. Система захоронения РАО в случае вывода из эксплуатации ПУГР - это совокупность природно-геологических образований (вмещающие и покрывающие породы), шахты УГР и приреакторных помещений (объект захоронения), захораниваемых PAO (облученный графит - основной источник активности) и создаваемых инженерных барьеров безопасности.

При создании пункта консервации «особых» РАО требуется его непрерывный мониторинг с целью перевода в пункт захоронения «особых» РАО. Основным критерием, определяющим возможность такого перевода, является стабильность дополнительных барьеров безопасности в течение всего срока наблюдения. Для этого требуется разработка новых методов и подходов, направленных на поддержание основных функций глиносодержащих барьеров безопасности, и их восстановление в случае природного или техногенного воздействия.

В промышленности, геологии и строительстве широко применяется электроосмотический метод осушения грунта и инженерных сооружений, основанный на явлении движения жидкости через пористые материалы или капилляры при наложении внешнего электрического поля [8-10]. Особенностью используемого при ВЭ ЯРОО глиносодержащего барьерного материала является его способность при нормальных условиях не пропускать жидкость $[11,12]$. При обводнении такого барьера происходит образование тонких каналов, которые обладают свойствами капилляров. Следовательно, на жидкость, обводняющую барьерный материал, можно воздействовать внешним электрическим полем. Это создает условия для осушения и восстановления материала барьера.

Поэтому целью настоящего исследования является разработка и апробация способа осушения барьеров безопасности на основе природных глин, используемых при ВЭ ЯРОО, электроосмотическим методом.

\section{Особенности барьерного материала на основе природных глин}

Барьерный материал, используемый при создании дополнительных барьеров безопасности при ВЭ ЯРОО, должен удовлетворять следующим критериям: неселективность при сорбции различных по химическим свойствам радионуклидов; отсутствие компонентов, способных повышать мобильность радионуклидов при эксплуатации барьера; низкая водопроницаемость; стабильность свойств барьера в течение периода эксплуатации; экологическая безопасность; низкие коэффициенты диффузии при нормальных условиях эксплуатации и высокая сорбционная способность по отношению к радионуклидам, в первую очередь, к актинидам и долгоживущим ${ }^{14} \mathrm{C}$ и ${ }^{36} \mathrm{Cl}$; стабильность свойств на период сохранения потенциальной опасности PAO; стабильность свойств барьера в различных по уровню водонасыщенности породах; экологическая безопасность; доступность; экономическая обоснованность. Кроме того, глиносодержащий барьерный материал должен быть совместим с геологической средой в местах размещения ЯРОО.

Исследования широкого спектра глинистых композиций привели к выводам, что для надежной изоляции РАО, образующихся при ВЭ ЯРОО, материал на основе глин должен иметь следующие характеристики [13-15]:

- размер зерен во фракциях, определяющих минералогический состав материала: $<0,01 \mathrm{Mм}$ более 50 \% мас.; содержание фракции с размером частиц $<0,005$ мм не менее $40 \%$ мас.;

- емкость катионного обмена (ЕКО) - более 20 мг-экв/100 г материала;

- коэффициент распределения изотопов $\mathrm{Pu}, \mathrm{Cs}$, $\mathrm{U}$ - более $7 \cdot 10^{2} \mathrm{~cm}^{3} / \mathrm{r}$;

- содержание фракции с размером частиц $<0,1 \mathrm{~mm}$ - не менее 80 \% мас. от общего количества материала;

- фактор задержки (для случая наличия движения влаги в материале - отношение скорости миграции радионуклидов к скорости движения влаги) - не менее 100 ;

- влажность - не более 3-4 \% мас.

В полном объеме требованиям, предъявляемым при создании искусственных барьеров безопасности, отвечают бентонитовые глины, состоящие в основном из монтмориллонита $(\geq 60 \%)$ и имеющие в качестве обменного катиона натрий [16]. Бентонитовые глины с другими обменными катионами могут иметь коэффициенты фильтрации $\left(K_{\phi}\right)$ на два порядка выше. Если для Na-формы $K_{\phi}=9,3 \cdot 10^{-9} \mathrm{~cm} / \mathrm{c}$, то, например, при замене натрия на трехвалентное железо значение коэффициента фильтрации возрастает до $1,1 \cdot 10^{-7} \mathrm{~cm} / \mathrm{c}$ [17]. Натрий, находящийся в обменной форме, оказывает наибольшее диспергирующее воздействие, приво- 
дящее к уменьшению размера частиц глинистых материалов. Кроме того, обменные катионы влияют на проницаемость пород, регулируя природу и мощность пленок воды, адсорбированных на поверхности глинистых материалов [18]. Мощные слои адсорбированной воды на поверхности чешуек монтмориллонита, насыщенного натрием, препятствуют ее фильтрации вследствие уменьшения диаметра пор и затрудняют движение вдоль поверхности слоя слабо ориентированных молекул адсорбированной воды.

Низкая гидравлическая проводимость является одним из основных требований, предъявляемых к глинистым материалам, используемым для изготовления защитных барьеров безопасности в хранилищах ТРО. Вследствие того, что для изготовления искусственных барьеров, как правило, используются несвязные грунты, их гидравлическая проводимость определяется не только минералогическим составом глин, но и зависит от степени их уплотнения. Уплотнение до 1,3-1,5 г/ $\mathrm{cm}^{3}$ не обеспечивает глинам надежной водонепроницаемости. Только уплотненные до $~ 2,0$ г/ $\mathrm{cm}^{3}$ при оптимальной влажности (16-26\%) все глины становятся влагонепроницаемыми [19]. Однако в действующих хранилищах при изготовлении в них дополнительных барьеров безопасности практически невозможно использовать операции уплотнения глинистых материалов без разборки или перегрузки ТРО. Таким образом, получить водонепроницаемые глины можно только за счет изменения их минералогического состава, например, за счет введения в них модификаторов (например, бентонита). Содержание илистой фракции в образцах должно изменяться от 18 до 28 \% мас., тонкопылеватой фракции - от 34 до 50 \% мас., то есть значительная часть породы должна состоять из тонкодисперсного материала, катионообменная емкость которого больше 30 мг-экв. $/ 100$ г породы [6, 20, 21].

Глиносодержащий барьерный материал, удовлетворяющий указанным свойствам, был разработан Институтом физической химии и электрохимии им. А.Н. Фрумкина Российской академии наук (г. Москва) совместно с 000 «ПИК» (г. Красноярск) и использовался при выводе из эксплуатации ПУГР на площадках ФГУП «ГХК» (г. Железногорск) и $\mathrm{AO}$ «СХК» (г. Северск).

\section{Разработка экспериментального стенда}

Исходя из анализа теоретических основ процесса капиллярного движения жидкости под действием электрического поля и с учётом особенностей барьерного материала был разработан экспериментальный стенд (рис. 1) для оценки возможности осушения глиносодержащих барьеров безопасности электроосмотическим методом. Барьерный материал - 1 на основе бентонитовой глины, который использовался для создания дополнительных барьеров безопасности при ВЭ ПУГР АД ФГУП «ГХК», размещался внутри прозрачной стеклянной емкости - 2 объёмом $0,033 \mathrm{~m}^{3}$. Используемый барьерный материал - 1 объёмом 0,02 м³ выдерживался в емкости - 2 в течение 48 часов при комнатной температуре и атмосферном давлении с целью дополнительного самоуплотнения. После этого производилось измерение плотности и влажности. Плотность глиносодержащего барьерного материала на момент начала экспериментов составляла 1,55 г/ $\mathrm{cm}^{3}$, а влажность, измеренная многофункциональным измерительным прибором Testo 645 , не превышала $3 \%$.

В барьерный материал - 1, размещённый в стенде-имитаторе ЯРОО - 2, устанавливались перфорированные электроды (3 - анод, 4 - катод), выполненные из высоколегированной стали марки 02Х8Н22C6 (ЭП794). Анод - 3 и катод - 4 соединялись с источником постоянного тока - 5 GPC3060D марки GW Instek со стабилизацией выходного напряжения, способным создавать разность потенциалов в диапазоне (0,01-32) В. Максимальная сила тока при этом могла достигать до $12 \mathrm{~A}$. Для определения скорости движения влаги стендимитатор был снабжён шкалой - 6. Изменение фронта движения жидкости фиксировалось с помощью камеры - 7. При проведении экспериментов в качестве постоянных параметров выбирались: подаваемое на электроды напряжение, объём глиносодержащего барьерного материала, количество обводняющего раствора в начальный момент времени. Изменяемыми параметрами являлись: сила тока, электропроводность глиносодержащего барьерного материала, расстояние между электродами, качественный состав растворов и время проведения эксперимента.

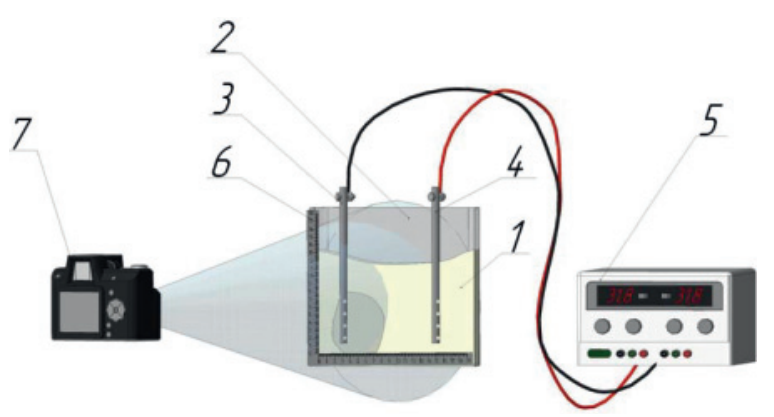

Pис. 1. Схема экспериментальной установки

Fig. 1. Scheme of experimental installation

С целью определения скорости электроосмотического движения модельного раствора от одного электрода к другому напротив прозрачной емкости - 2 была установлена цифровая фотокамера, которая фиксировала изменение положения фронта жидкости. В качестве модельных растворов использовалась вода, содержащая соли магния, натрия и кальция. Имитировалась ситуация возможного обводнения пункта приповерхностного захоронения радиоактивных отходов (ППЗРО) - paствор № 1 и пункта глубинного захоронения радиоактивных отходов (ПГЗРО) - раствор № 2. Химический состав растворов представлен в табл. 1. 
Таблица 1. Химический состав модельных растворов

Table 1. Chemical composition of standard test solution

\begin{tabular}{|c|c|}
\hline Емкость/Tank & Состав/Composition \\
\hline \multirow{4}{*}{1} & $\mathrm{NaHCO}_{3}$ \\
\cline { 2 - 2 } & $\mathrm{MgSO}_{4} \cdot 7 \mathrm{H}_{2} \mathrm{O}$ \\
\cline { 2 - 2 } & $\mathrm{CaCl}_{2} \cdot 6 \mathrm{H}_{2} \mathrm{O}$ \\
\cline { 2 - 2 } & $\mathrm{MgCO}_{3}$ \\
\hline \multirow{2}{*}{2} & $\mathrm{NaHCO}_{3}$ \\
\cline { 2 - 2 } & $\mathrm{MgSO}_{4} \cdot 7 \mathrm{H}_{2} \mathrm{O}$ \\
\cline { 2 - 2 } & $\mathrm{CaCl}_{2} \cdot 6 \mathrm{H}_{2} \mathrm{O}$ \\
\hline
\end{tabular}

Стоит отметить, что в растворе № 1 содержание $\mathrm{NaHCO}_{3}$ не превышало $7 \mathrm{mг} / л, \mathrm{MgSO}_{4} \cdot 7 \mathrm{H}_{2} \mathrm{O}$ $<38$ мг/л, $\mathrm{CaCl}_{2} \cdot 6 \mathrm{H}_{2} \mathrm{O}-225 \mathrm{мг} /$ л, $\mathrm{MgCO}_{3}-3 \mathrm{мг} / л$. В растворе № 2 концентрация $\mathrm{NaHCO}_{3}$ составляла не более $320 \mathrm{мг} / л, \mathrm{MgSO}_{4} \cdot 7 \mathrm{H}_{2} \mathrm{O}$ - $<85 \mathrm{мг} / л$, $\mathrm{CaCl}_{2} \cdot 6 \mathrm{H}_{2} \mathrm{O}-195$ мг/л.

\section{Исследование процесса восстановления глиносодержащих барьеров безопасности}

В лабораторных условиях был подготовлен раствор № 1, имитирующий грунтовые воды вблизи одного из ППЗРО. Расстояние между электродами составляло 90 мм. В полый электрод, являющийся анодом, закачивали раствор № 1 и под давлением подавали в перфорированную область. В результате происходило симметричное обводнение электрода. Через 10 минут после обводнения между электродами создавали разность потенциалов $31,8 \mathrm{~B}$. В первые минуты наблюдалось наиболее интенсивное движение фронта жидкости, причём перемещение происходило в строго выделенном горизонтальном направлении от анода к катоду (рис. 2, кривая 1). Линейная скорость движения отстающего фронта в этом случае изменялась в диапазоне $(0,9-1,4) \mathrm{Mm} /$ мин в первые 10 минут после создания разности потенциалов. Стоит отметить, что, несмотря на силу тяжести, влага практически не распространялась в вертикальном направлении. Объясняется это, во-первых, слоистой структурой глиносодержащего барьера безопасности, а во-вторых, электроосмотическим эффектом, осложнённым диффузией и электромиграцией. Последнее возникало за счёт диссоциации молекул солей $\left(\mathrm{MgSO}_{4}, \mathrm{CaCl}_{2}, \mathrm{MgCO}_{3}, \mathrm{NaHCO}_{3}\right)$ на ионы, которые увеличивали подвижность раствора в целом (о чём свидетельствует протекание электрического тока).

Через 20-30 минут после начала ведения процесса линейная скорость движения фронта жидкости снизилась и стабилизировалась. Величина её составила 0,3-0,6 мм/мин. При этом сам фронт выровнялся в вертикальном направлении. Вероятно, это связано с тем, что скорость (линейная и объёмная) лимитировалась количеством подаваемого раствора, а процесс продолжался только при протекании постоянного или возрастающего тока. Для увеличения эффективности рассматриваемого способа необходимо размещать электроды как можно ближе к области обводнения.

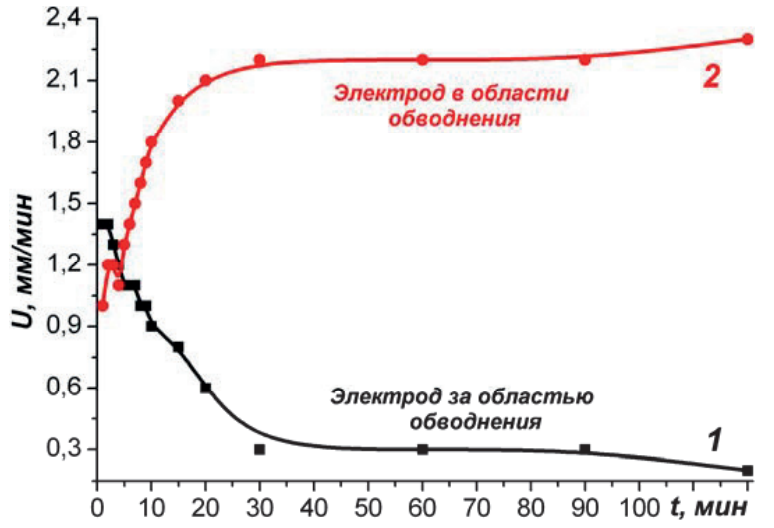

Рис. 2. Изменение скорости движения жидкости между әлектродами с течением времени: 1 - раствор № 1; 2 - раствор № 2

Fig. 2. Liquid velocity variation in time: 1 - solution № 1; 2 - solution № 2

После завершения процесса осушения барьеров безопасности электроды удалялись из глиносодержащего барьерного материала. При этом наблюдалось спекание, омоноличивание и прилипание глины к аноду. Плотность образованного монолита оценивалась в 2-4 г/ $\mathrm{cm}^{3}$. Это позволило извлечь электрод с деградированным барьерным материалом.

Образованный на электроде монолит практически не удаляется водой и его разрушение возможно только при механическом воздействии. После очистки электрода наблюдается ярко выраженное изменение его цвета на темно-жёлтый. Изменение цвета носит объёмный характер. Вероятно, это связано, с протеканием химических реакций на поверхности электрода, а именно с образованием сульфатов, карбидов и хлоридов металлов, из которых он состоит.

Также в лабораторных условиях был воссоздан раствор, имитирующий грунтовые воды в ПГЗРО. Расстояние между электродами в первой серии экспериментов составляло 70 мм, в анод закачивался раствор объёмом 50 мл, разность потенциалов между электродами не превышала 31,8 В. Изображения емкости с обводненным электродом в начальный момент времени и через 120 минут представлены на рис. 3. Как видно из рис. 3, происходило практически симметричное обводнение анода. Суммарная линейная скорость капиллярного, диффузионного и электромиграционного движения жидкости составляла 0,02 мм/мин. Это говорит о том, что барьеры безопасности на основе бентонита сдерживали продвижение раствора, имитирующего грунтовые воды из ПГЗРО.

С целью оценки возможности использования электроосмотического эффекта для восстановления барьеров безопасности после обводнения грунтовыми водами из ПГЗРО расстояние между электродами было уменьшено до 40 мм (рис. $4, a)$.

Это привело к возникновению электрического тока, протекающего по всему объёму глины, за- 


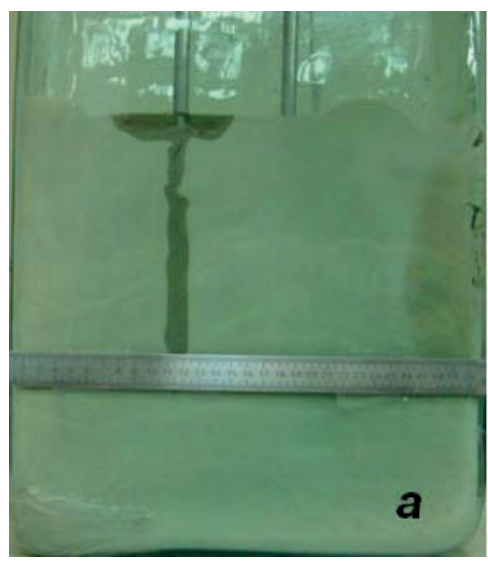

$a / a$

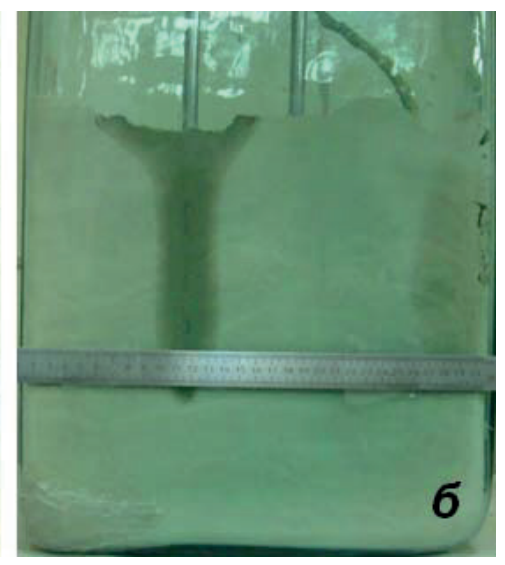

$6 / b$

Рис. 3. Состояние барьеров безопасности в момент обводнения водой из ПГЗРО (а) и через 120 минут (б)

Fig. 3. State of safety barriers in time of drowning by water from depth disposal (a) and in 120 minutes (b)

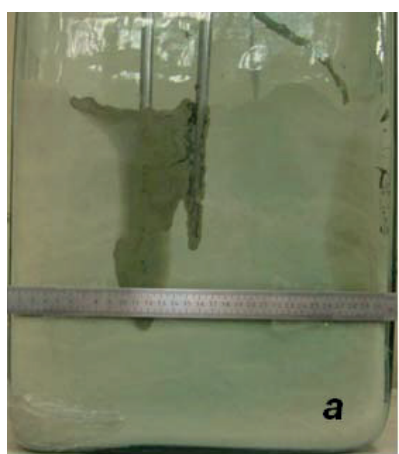

$a / a$

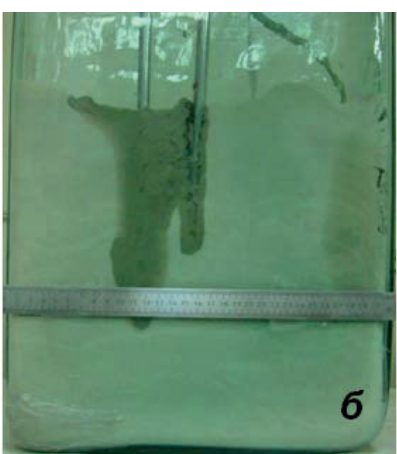

$\sigma / b$

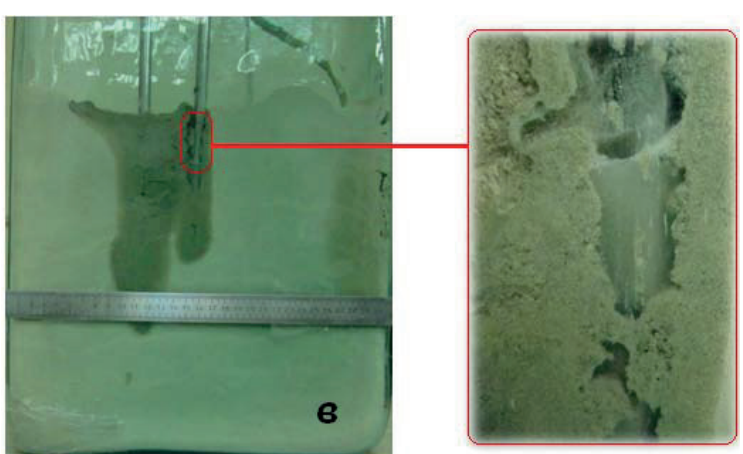

$B / c$

Pис. 4. Состояние барьеров безопасности в различные промежутки времени после перелещения электрода через: а) 1 минуту; б) 10 линут; в) 30 минут

Fig. 4. State of safety barriers in different interval after displacement of electrode in: a) 1 minute; b) 10 minutes; c) 30 minutes

ключенной между электродами. Величина силы тока в первые минуты составила 30-40 мА, через 30 мин - 50-70 мА. Происходило лавинообразное увеличение свободных носителей заряда (ионов солей), в результате чего линейная скорость движения влаги превысила 2,5 мм/мин (рис. 4, б, рис. 2, кривая 2).

Визуально можно было наблюдать, что мелкие гранулы барьерного материала вместе с раствором образовывали макрокапилляры и по ним перемещались в прикатодную область. За первые 30 мин протекания процесса примерно 1/2 длины катода была обводнена раствором из прианодной области (рис. 4,6$)$. С течением времени происходило повышение уровня жидкости вокруг катода, при этом образовывались полости, через которые можно было удалять жидкость. В прикатодной области наблюдалось интенсивное газообразование, которое приводило к удалению части раствора. При этом область вокруг анода в течение последующих 60-70 мин стала заметно суше.

После проведения экспериментов по осушению глиносодержащих барьеров безопасности проводили оценку изменения фильтрационных и абсорбционных свойств барьерного материала. Для этого определяли его насыпную плотность $\rho$, коэффициент фильтрации $K_{\phi}$ и коэффициент межфазного распределения $K_{d}$ до и после процесса осушения барьера безопасности в различных областях лабораторного стенда-имитатора. Области отбора проб показаны на рис. 5 .

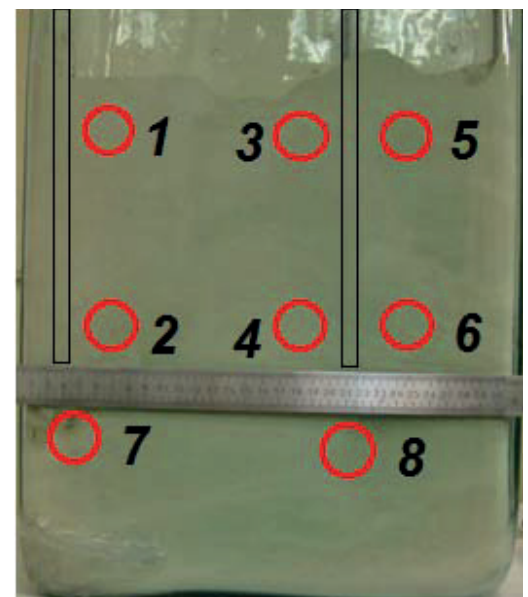

Pис. 5. Области отбора проб осушенного барьерного материала

Fig. 5. Sampling areas of dried barrier material 
Пробы исходного глиносодержащего барьерного материала отбирались в областях, указанных на рис. 5. Всего было отобрано 32 пробы на два эксперимента (по 16 на каждый), в которых имитировалось обводнение барьеров безопасности грунтовыми водами в ППЗРО и ПГЗРО. Данные работы проводились для определения влияния вторичного минералообразования в объёме породы между электродами, а также в областях под электродами.

Насыпная плотность барьерного материала ? определялась путем сравнения массы отобранной пробы с её объёмом. Коэффициент фильтрации определяли путем послойного размещения отобранного барьерного материала в стеклянной трубке, её последующего заполнения водой, определения уровня жидкости и границы смачивания породы. Расчет $K_{\phi}$ проводили по формуле (1):

$$
K_{\phi}=\frac{Q}{S I \tau},
$$

где $Q$ - объём воды, $\mathrm{cm}^{3} ; S$ - площадь поперечного сечения стеклянной трубки, см$^{2} ; \tau$ - время, с; $I-$ гидравлический градиент, определяемый по формуле (2):

$$
I=\frac{H}{l},
$$

здесь $H$ - гидравлический напор, см; $l$ - длина пути фильтрации, см.

Площадь поперечного сечения стеклянной трубки, в которой проводили эксперименты по определению коэффициентов фильтрации, составлял $3,14 \mathrm{~cm}^{2}$. Объём воды, подаваемый в верхнюю часть стеклянной трубки, не превышал $15,7 \mathrm{~cm}^{3}$. Время проведения каждого эксперимента составляла 20 суток (1728000 с). Наблюдаемая длина пути фильтрации не превышала 0,1 см за все время проведения экспериментов.

Также определяли коэффициент межфазного распределения радионуклида ${ }^{137} \mathrm{Cs}$ в глиносодержащем барьерном материале. Для этого отобранные образцы обводняли водой, содержащей известное количество указанного радионуклида, а затем рассчитывали величину $K_{d}$ по формуле:

$$
K_{d}=\frac{C_{\mathrm{H}}-C_{\mathrm{\kappa}}}{C_{\mathrm{\kappa}}} \cdot \frac{V_{ж}}{m_{\text {тв }}},
$$

где $C_{\text {н }}$ и $C_{\text {к }}$ - начальная и конечная концентрация раствора (воды), Бк/л; $V_{\text {ж }}$ объём раствора (воды), л; $m_{\text {тв}}$ - масса глиносодержащего барьерного материала, г.

Перед началом экспериментов по определению коэффициента межфазного распределения $K_{d}$ проводилось измерение удельной активности радионуклида ${ }^{137} \mathrm{Cs}$ в пробах воды. Значение величины $C_{\text {н }}$ составляло 2 кБк/л.

Результаты определения насыпной плотности $\rho$, коэффициента фильтрации $K_{\phi}$ и коэффициента межфазного распределения $K_{d}$ до и после осушения материала барьера в различных областях лабораторного стенда-имитатора приведены в таб. 2,3 .
Таблица 2. Результаты определения свойств барьерного материала при обводнении раствором № 1

\begin{tabular}{|c|c|c|c|c|c|c|}
\hline \multirow{2}{*}{$\begin{array}{l}\text { Область отбора } \\
\text { проб } \\
\text { Sampling point }\end{array}$} & \multicolumn{2}{|c|}{$\rho, \Gamma / \mathrm{cm}^{3} / \mathrm{g} / \mathrm{cm}^{3}$} & \multicolumn{2}{|c|}{$K_{\phi}, \mathrm{cm} / \mathrm{c}(\mathrm{cm} / \mathrm{s})$} & \multicolumn{2}{|c|}{$K_{d}, \mathrm{~cm}^{3} / \Gamma\left(\mathrm{cm}^{3} / \mathrm{g}\right)$} \\
\hline & $\begin{array}{c}\text { до } \\
\text { before }\end{array}$ & $\begin{array}{l}\text { после } \\
\text { after }\end{array}$ & $\begin{array}{c}\text { до } \\
\text { before }\end{array}$ & $\begin{array}{l}\text { после } \\
\text { after }\end{array}$ & $\begin{array}{c}\text { до } \\
\text { before }\end{array}$ & $\begin{array}{l}\text { после } \\
\text { after }\end{array}$ \\
\hline 1 & 1,55 & 1,51 & $1,0 \cdot 10^{-6}$ & 0 & $3,4 \cdot 10^{3}$ & $3,5 \cdot 10^{3}$ \\
\hline 2 & 1,55 & 1,52 & 0 & 0 & $3,3 \cdot 10^{3}$ & $3,5 \cdot 10^{3}$ \\
\hline 3 & 1,58 & 1,52 & $0,5 \cdot 10^{-6}$ & 0 & $3,3 \cdot 10^{3}$ & $3,4 \cdot 10^{3}$ \\
\hline 4 & 1,53 & 1,52 & 0 & 0 & $3,7 \cdot 10^{3}$ & $2,2 \cdot 10^{3}$ \\
\hline 5 & 1,54 & 1,54 & $1,0 \cdot 10^{-6}$ & $2,5 \cdot 10^{-6}$ & $3,6 \cdot 10^{3}$ & $2,8 \cdot 10^{3}$ \\
\hline 6 & 1,60 & 1,55 & 0 & 0 & $3,6 \cdot 10^{3}$ & $3,7 \cdot 10^{3}$ \\
\hline 7 & 1,55 & 1,59 & 0 & 0 & $3,3 \cdot 10^{3}$ & $4,0 \cdot 10^{3}$ \\
\hline 8 & 1,59 & 1,59 & 0 & 0 & $3,3 \cdot 10^{3}$ & $4,1 \cdot 10^{3}$ \\
\hline
\end{tabular}

Table 2. Results of determination of barrier material properties under water invasion by solution no. 1

таблица 3. Результаты определения свойств барьерного материала при обводнении раствором № 2

Table 3. Results of determination of barrier material properties under water invasion by solution no. 2

\begin{tabular}{|c|c|c|c|c|c|c|}
\hline \multirow{2}{*}{\begin{tabular}{c} 
Область отбора $\begin{array}{c}\text { проб } \\
\text { Sampling point }\end{array}$ \\
\cline { 2 - 7 }
\end{tabular}} & $\begin{array}{c}\rho, \text { до } \\
\text { before }\end{array}$ & $\begin{array}{c}\text { после } \\
\text { after }\end{array}$ & $\begin{array}{c}\text { до } \\
\text { before }\end{array}$ & $\begin{array}{c}\text { после } \\
\text { after }\end{array}$ & $\begin{array}{c}\text { до } \\
\text { before }\end{array}$ & $\begin{array}{c}\text { после } \\
\text { after }\end{array}$ \\
\hline 1 & 1,53 & 1,53 & $2,5 \cdot 10^{-6}$ & $1,0 \cdot 10^{-7}$ & $3,3 \cdot 10^{3}$ & $3,0 \cdot 10^{3}$ \\
\hline 2 & 1,53 & 1,53 & 0 & $2,0 \cdot 10^{-6}$ & $3,2 \cdot 10^{3}$ & $2,2 \cdot 10^{3}$ \\
\hline 3 & 1,55 & 1,53 & $0,5 \cdot 10^{-6}$ & $2,5 \cdot 10^{-6}$ & $3,4 \cdot 10^{3}$ & $3,1 \cdot 10^{3}$ \\
\hline 4 & 1,55 & 1,56 & 0 & $1,0 \cdot 10^{-6}$ & $3,5 \cdot 10^{3}$ & $2,9 \cdot 10^{3}$ \\
\hline 5 & 1,55 & 1,56 & $0,5 \cdot 10^{-6}$ & $2,0 \cdot 10^{-6}$ & $3,4 \cdot 10^{3}$ & $3,0 \cdot 10^{3}$ \\
\hline 6 & 1,60 & 1,56 & 0 & 0 & $3,3 \cdot 10^{3}$ & $2,9 \cdot 10^{3}$ \\
\hline 7 & 1,59 & 1,58 & 0 & 0 & $3,4 \cdot 10^{3}$ & $3,8 \cdot 10^{3}$ \\
\hline 8 & 1,60 & 1,57 & 0 & 0 & $3,4 \cdot 10^{3}$ & $3,8 \cdot 10^{3}$ \\
\hline
\end{tabular}

Из результатов, представленных в табл. 3, 4, видно, что в процессе осушения глиносодержащих барьеров безопасности в лабораторном стенде-имитаторе плотность барьерного материала существенно не меняется. Кроме того, при удалении раствора № 1, имитирующего грунтовые воды вблизи одного из ППЗРО, сохраняются некоторые фильтрационные свойства барьерного материала, а именно коэффициент фильтрации $K_{\phi}$. При проведении экспериментов по определению указанного параметра перемещение жидкости в стеклянной трубке практически отсутствовало. Однако при осушении барьеров безопасности, обводнённых раствором № 2, имитирующим грунтовые воды вблизи одного из ПГЗРО, происходило незначительное увеличение коэффициента фильтрации. Особенно это характерно для верхних слоёв глиносодержащего барьерного материала. Возможно, незначительное увеличение $K_{\phi}$ связано с погрешностью измерений, а также с однократным проведением эксперимента. Стоит обратить внимание, что после осушения глиносодержащих барьеров безопасности происходит незначительное изменение коэффициента межфазного распределения $K_{d}$ радионуклида ${ }^{137} \mathrm{Cs}$. При этом в некоторых случаях указанный параметр уменьшается в 1,5 раза (табл. 2, область отбора проб № 2). Однако допустимое изменение величины $K_{d}$ для рассматриваемого барьерного материала составляет $(2-4) \cdot 10^{3} \mathrm{~cm}^{3} /$ Г. 
Таким образом, при использовании электроосмотического метода для осушения глиносодержащих барьеров безопасности в лабораторных условиях на стенде-имитаторе не было выявлено существенных изменений фильтрационных и абсорбционных свойств, вызванных процессами вторичного минералообразования в объёме породы между электродами. Возможно, описанная тенденция не сохранится при масштабировании эксперимента или проведении процесса осушения в ПГЗРО и ППЗРО. Однако для проверки данного утверждения необходимо проведение отдельных исследований.

\section{Заключение}

В работе было показано, что для создания дополнительных барьеров безопасности при ВЭ ЯРОО могут быть использованы барьерные материалы на основе природных глин (например, бентонита). Однако такие барьеры безопасности могут быть подвержены внешнему негативному воздействию (техногенному или природному), что приводит к частичному ухудшению их противофильтрационных и противомиграционных свойств. Для восстановления целостности и работоспособности глиносодержащих барьеров безопасности целесообразно использовать методы, не приводящие к существенной деградации барьерного материала. Для этих целей возможно использование электроосмотического метода, основанного на капиллярном движении влаги в электростатическом поле. Предложенный электроосмотический метод восстановления глиносодержащих барьеров безопасности позволяет концентрировать влагу возле од-

\section{СПИСОК ЛИТЕРАТУРЫ}

1. Updating irradiated graphite disposal: Project «GRAPA» and the international decommissioning network / A. Wickham, H.-J. Steinmetz, P. O'Sullivan, M.I. Ojovan // Journal of Environmental Radioactivity. - 2017. - V. 171. - P. 34-40.

2. Радиоактивный реакторный графит. Монография / А.В. Бушуев, А.Ф. Кожин, Е.В. Петрова, В.Н. Зубарев, Т.Б. Алеева, Н.А. Гирке. - М.: Национальный исследовательский ядерный университет МИФИ, 2015. - 148 с.

3. IAEA, Processing of Irradiated Graphite to meet Acceptance Criteria for Waste Disposal. Results of a coordinated research project, Technical Report Series. - Vienna: IAEA, 2016. - № 1690. URL: https://www-pub.iaea.org/MTCD/Publications/PDF/TE1790 web.pdf (дата обращения 15.08.2018).

4. IAEA, Progress in Radioactive Graphite Waste Management, Technical Report Series No. 1647. - Vienna: IAEA, 2016. № 1690. URL: https://www-pub.iaea.org/MTCD/Publications/PDF/TE-1790 web.pdf (дата обращения 15.08.2018).

5. Izmestiev A., Pavliuk A., Kotlyarevsky S. Application of voidfree filling technology for additional safety barriers creation during uranium-graphite reactors decommissioning // Advanced Materials Research. - 2015. - V. 1084. - P. 613-619.

6. Experience of on-site disposal of production uranium-graphite nuclear reactor / A.O. Pavliuk, S.G. Kotlyarevskiy, E.V. Bespala, E.V. Zakharova, V.M. Ermolaev, A.G. Volkova // Journal of Environmental Radioactivity. - 2018. - V. 184-185. - P. 22-31. ного из электродов, тем самым осушая прилегающую область глины.

Показано, что наибольшая скорость удаления влаги достигается в экспериментах с растворами, имитирующими грунтовые воды из ПГЗРО. Так, при напряжении 31,8 В и расстоянии между электродами 40 мм линейная скорость движения влаги составляет 2,5 мм/мин. Это позволяет осушить слой глиносодержащего барьера безопасности, находящийся между электродами в стенде-имитаторе, обводненный 70 мл раствора, в течение 7-8 часов.

Выявлено, что в результате рекомбинации диссоциированных ионов солей и воды на электродах происходит прилипание, спекание и омоноличивание барьерного материала в приэлектродной области. Это позволяет удалить деградированный барьерный материал вместе с электродом. Кроме того, установлено, что в области концентрирования влаги вблизи катода происходят химические реакции, результатом которых является выделение газообразных продуктов. Это позволяет удалять жидкость без использования специальных средств в непрерывном режиме.

Таким образом, в ходе настоящей работы была показана возможность применения электроосмотического эффекта для однократного осушения барьеров безопасности, находящихся в стендахимитаторах хранилищ ЯРОО. Стоит отметить, что представленные результаты получены в лабораторных условиях и для полной оценки эффективности использования данного метода (включая хранилища РАО) требуется проведение экспериментов как минимум на укрупнённых стендах.

7. Чубреев Д.О., Кузнецов Г.В. Использование глинистых материалов для создания барьера безопасности выводимого из эксплуатации реактора АД // Известия Томского политехнического университета. Инжиниринг георесурсов. - 2016. - Т.327. - № 2. - С. 83-87.

8. Кадет В.В., Корюзлов П.С. Экспериментальное исследование электроосмотического течения в тонких щелевых каналах // Прикладная механика и техническая физика. - 2009. T. 50. - № 5. - C. 90-94.

9. Electrodynamics near hydrophobic surface / S.R. Maduar, A.V. Belyaev, V. Lobaskin, O.I. Vinogradova // Physical review letter. - 2015. - V. 114. - P. 118301-1-118301-5. D0I: 10.1103/PhysRevLett.114.118301

10. Сологаев В.И. 0 применении электроосмоса при защите от подтопления земель // Вестник Омского ГАУ. - 2017. - № 3 (27). C. $122-129$.

11. Антоненко М.В., Чубреев Д.О., Кузнецов Г.В. Моделирование процесса диффузии радиоуглерода из активной зоны выводимого из эксплуатации ПУГР АД // Атомная энергия. - 2015. T. $118 .-$ C. $63-68$.

12. Сорбционные характеристики материалов фильтрационного барьера в верхних водоносных горизонтах, загрязненных радионуклидами / Н.Д. Андрющенко, А.В. Сафонов, Т.Л. Бабич, П.В. Иванов, Ю.В. Коневник, А.А. Кондрашова, И.М. Прошин, Е.В. Захарова // Радиохимия. - 2017. - Т. 59. - № 4. C. $361-370$. 
13. Experimental simulation of the radionuclide behaviour in the process of creating additional safety barriers in solid radioactive waste repositories containing irradiated graphite / A.0. Pavliuk, S.G. Kotlyarevskiy, E.V. Bespala, E.V. Zakarova, N.I. Rodygina, V.M. Ermolaev, I.M. Proshin, A.G. Volkova // IOP Conf. Series: Materials Science and Engineering. - 2016. - № 142. - P. 1-7.

14. Моделирование процесса миграции долгоживущих радионуклидов из графитовых радиоактивных отходов / А.О. Павлюк, С.Г. Котляревский, Е.В. Беспала, А.Г. Волкова, Е.В. Захарова, Н.Д. Андрющенко // Известия Томского политехнического университета. Инжиниринг георесурсов. - 2017. - Т. 328. № 4. - C. $75-84$.

15. Investigation and Modeling of Cesium (I) Adsorption by Turkish Clays: Bentonite, Zeolite, Sepiolite, and Kaolinite / S. Bayulken, E. Bascetin, K. Guclu, R. Apak // Environmental Progress \& Sustainable Energy. - 2011. - V. 30. - № 1. - P. 70-80.

16. Сорбционные характеристики апатита и вермикулита по отношению к радионуклидам цезия и стронция / А.А. Кондрашова, Н.Д. Андрющенко, Е.В. Захарова, Е.А. Тюпина // Успехи в химии и химической технологии. - 2016. - Т. 30. - № 6 (175). C. $56-58$.
17. 0 моделировании сорбции стронция на породах в условиях высокой засоленности раствора нитратом натрия / К.А. Болдырев, И.В. Капырин, Л.И. Константинова, Е.В. Захарова // Радиохимия. - 2016. - Т. 53. - № 3. - С. 211-217.

18. Behavior of $\mathrm{Cs}, \mathrm{Np}(\mathrm{V}), \mathrm{Pu}(\mathrm{IV})$, and $\mathrm{U}$ (VI) in pore water of Bentonite / M.N. Sabodina, S.N. Kalmykov, K.A. Artem'eva, E.V. Zakharova, Yu.A. Sapozhnikov // Radiochemistry. 2006. - V. 48. - № 5. - P. 488-492.

19. Regularities of the sorption behavior of actinide ions on mineral colloid particles / A.Yu. Romanchuk, S.N. Kalmykov, A.P. Novikov, E.V. Zakharova // Russian Journal of General Chemistry. 2011. - V. 81. - № 9. - P. 2029-2038.

20. Мартынов К.В., Коневник Ю.В., Захарова Е.В. Барьерные свойства кристаллических горных пород при миграции радионуклидов // Радиохимия. - 2017. - Т. 59. - № 4. - С. 371-378.

21. Взаимодействие радионуклидов с техногенно преобразованными породами / Е.П. Каймин, А.А. Графчиков, Е.В. Захарова, Л.И. Константинова // Геоэкология. Инженерная геология. Гидрогеология. Геокриология. - 2008. - № 1. - С. 29-38.

Поступила 10.12.2018 г.

\section{Информация об авторах}

Антоненко М.B., кандидат технических наук, заместитель главного инженера предприятия (энергетика), Федеральное государственное унитарное предприятие «Горно-химический комбинат» .

Леонов А.В., директор Реакторного завода, Федеральное государственное унитарное предприятие «Горно-химический комбинат».

Беспала E.B., кандидат физико-математических наук, ведущий инженер Опытно-технологической лаборатории Реакторного завода, Федеральное государственное унитарное предприятие «Горно-химический комбинат».

Чубреев Д.О., начальник Опытно-технологической лаборатории Реакторного завода, Федеральное государственное унитарное предприятие «Горно-химический комбинат».

Беспала Ю.Р., инженер, Федеральное государственное унитарное предприятие «Горно-химический комбинат». 
UDC 631.438.2; $544.034 .24 ; 532.5-1 /-9$

\title{
APPLICATION OF ELECTROOSMOTIC EFFECT FOR UNWATERING SAFETY BARRIERS DURING DECOMMISSIONING NUCLEAR LEGACY
}

\author{
Mikhail V. Antonenko', \\ antonenkomv26@mail.ru \\ Aleksey V. Leonov', \\ leonovav26@mail.ru \\ Evgeny V. Bespala', \\ bespala_evgeny@mail.ru \\ Dmitry 0. Chubreev', \\ d.chubreev@gmail.com \\ Yuliya R. Bespala', \\ yrbespala@gmail.com \\ ${ }^{1}$ Mining and Chemical Combine, \\ 53, Lenin street, Zheleznogorsk, Krasnoyarsk region, 662972, Russia.
}

The relevance of the discussed issue is caused by the need to develop new innovative non-destructive technologies of integrity reinstating and unwatering safety barriers based on mixture of natural clays, developed during decommissioning nuclear legacy.

The main aim of the study is to detect physical and chemical features of clay-based barrier materials, used at development of additional safety barriers during decommissioning nuclear legacy; as well as to design and implement the method of unwatering such barriers by electroosmotic effect.

The methods: analytical and experimental investigation of the electroosmotic effect occurred under unwatering safety barriers based on mixture of natural clays.

The results. The paper shows that the barrier materials based on bentonite used during decommissioning nuclear legacy are capable of retaining the unique antifiltering and antimigraion properties over the time of potential hazard of nuclear legacy object. The attention was accented on the fact that these safety barriers can be subjected to external negative impact (technogeneous or natural), that results in partial degradation of it antifiltering and antimigraion properties. It was proved that for integrity reinstating and working capacity of clay-based safety barriers it is appropriate to use the methods not resulting in degradation of barrier material. The authors propose to apply the electroosmotic method based on capillary flow of a fluid in electromagnetic field for these purposes. The stated electroosmotic method of integrity reinstating safety barriers allows accumulating liquid near one of electrode and thereby unwatering the adjacent area of clay. It is shown that the solution imitating groundwater is more effective removed from clay-based material from deep burial ground of radioactive waste. The linear travel of fluid was approximately 2,5 $\mathrm{mm} / \mathrm{min}$ at $31,8 \mathrm{~V}$ and distance between electrodes about $40 \mathrm{~mm}$. This allows draining completely a clay-based safety barrier, water-encroached by $70 \mathrm{ml}$ of solution during 7-8 hours. The authors revealed the adhesion, sintering and consolidation of barrier material at near-electrode area as a result of recombination of dissociated ions of saline and water on electrodes. This allows removing degraded barrier material coupled with electrode. Chemical reactions occur in the region of fluid accumulation near cathode and gases exude in this area. This allow exhausting liquid from clay without special devices in continuous regime.

Key words:

Nuclear legacy, barrier material, natural clays, decommissioning, electroosmosis, migration, radionuclide.

\section{REFERENCES}

1. Wickham A., Steinmetz H.-J., O'Sullivan P., Ojovan M.I. Updating irradiated graphite disposal: Project 'GRAPA' and the international decommissioning network. Journal of Environmental Radioactivity, 2017, vol. 171, pp. 34-40.

2. Bushuev A.V., Kozhin A.F., Petrova E.V., Zubarev V.N., Aleeva T.B., Girke N.A. Radioactioniy reaktorny grafit [The radioactive reactor graphite]. Moscow, National Research Nuclear University MIPhI Publ., 2015. 148 p.

3. IAEA, Processing of Irradiated Graphite to meet Acceptance Criteria for Waste Disposal. Results of a coordinated research project, Technical Report Series No. 1690. Vienna, IAEA, 2016, No. 1690. Available at: https://www-pub.iaea.org/MTCD/Publications/PDF/TE-1790_web.pdf (accessed 15 August 2018).

4. IAEA, Progress in Rádioactive Graphite Waste Management, Technical Report Series No. 1647. Vienna, IAEA, 2010, No. 1690.
Available at: https://www-pub.iaea.org/MTCD/Publications/PDF/TE-1790_web.pdf (accessed 15 August 2018).

5. Izmestiev A., Pavliuk A., Kotlyarevsky S. Application of voidfree filling technology for additional safety barriers creation during uranium-graphite reactors decommissioning. Advanced $\mathrm{Ma}$ terials Research, 2015, vol. 1084, pp. 613-619.

6. Pavliuk A.O., Kotlyarevskiy S.G., Bespala E.V., Zakharova E.V., Ermolaev V.M., Volkova A.G. Experience of on-site disposal of production uranium-graphite nuclear reactor. Journal of Environmental Radioactivity, 2018, vol. 184-185, pp. 22-31.

7. Chubreev D.0., Kuznetsov G.V. Using clay materials for developing safety barrier of decommissioning $\mathrm{AD}$ reactor. Bulletin of the Tomsk Polytechnic University, Geo Assets Engineering, 2016, vol. 327, no. 2, pp. 83-87. In Rus.

8. Kadet V.V., Koryuzlov P.S. Experimental investigation of electroosmotic flow in thin parallel-plate duct. Prikladnaya mekhanika $i$ tekhnicheskaya fizika, 2009, vol. 50, no. 5, pp. 90-94. In Rus. 
9. Maduar S.R., Belyaev A.V., Lobaskin V., Vinogradova O.I. Electrodynamics near hydrophobic surface. Physical review letter, 2015, vol. 114, pp. 118301-1-118301-5. DOI: 10.1103/PhysRevLett.114.118301

10. Sologaev V.I. 0 primenenii elektroosmosa pri zashchite ot podtopleniya zemel [To application of electroosmosis under underflooding protection]. Vestnik Omskogo GAU, 2017, no. 3 (27), pp. 122-129.

11. Antonenko M.V., Chubreev D.O., Kuznetsov G.V. Modeling of radiocarbon diffusion from the active zone of the decommissioned PUGP AD. Atomic Energy, 2015, vol. 118, pp. 63-68. In Rus.

12. Andryushchenko N.D., Safonov A.V., Babich T.L., Ivanov P.V., Konevnik Yu. V., Kondrashova A.A., Proshin I.M., Zakharova E.V. Sorption characteristics of the materials of the filtration barrier in the upper aquifers contaminated with radionuclides. Radiochemistry, 2017, vol. 59, no. 4, pp. 361-370. In Rus.

13. Pavliuk A.0., Kotlyarevskiy S.G., Bespala E.V., Zakharova E.V., Rodygina N.I., Ermolaev V.M., Proshin I.M., Volkova A.G. Experimental simulation of the radionuclide behaviour in the process of creating additional safety barriers in solid radioactive waste repositories containing irradiated graphite. IOP Conf. Series: Materials Science and Engineering, 2016, no. 142, pp. 1-7.

14. Pavlyuk A.0., Kotlyarevskiy S.G., Bespala E.V., Volkova A.G., Zakharova E.V., Andryushchenko N.D. Modelling migration process of long-lived radionuclides from graphite radioactive waste. Bulletin of the Tomsk Polytechnic University, Geo Assets Engineering, 2017, vol. 328, no. 4, pp. 75-84.

15. Bayulken S., Bascetin E., Guclu K., Apak R. Investigation and Modeling of Cesium (I) Adsorption by Turkish Clays: Bentonite,
Zeolite, Sepiolite, and Kaolinite. Environmental Progress \& Sustainable Energy, 2011, vol. 30, no. 1, pp. 70-80.

16. Kondrashova A.A., Andryushchenko N.D., Zakharova E.V., Tyupina E.A. Sorption characteristics of apatite and vermiculite in relation to cesium and strontium radionuclides. Successes in chemistry and chemical technology, 2016, vol. 30, no. 6 (175), pp. 56-58. In Rus.

17. Boldyrev K.A., Kapyrin I.V., Konstantinova L.I., Zakharova E.V. About modeling of strontium sorption on rocks under high salinity by sodium nitrate solution. Radiohimiya, 2016, vol. 53, no. 3, pp. 211-217. In Rus.

18. Sabodina M.N., Kalmykov S.N., Artem'eva K.A., Zakharova E.V., Sapozhnikov Yu.A. Behavior of Cs, Np (V), Pu (IV), and $\mathrm{U}$ (VI) in pore water of Bentonite. Radiochemistry, 2006, vol. 48, no. 5, pp. 488-492.

19. Romanchuk A.Yu., Kalmykov S.N., Novikov A.P., Zakharova E.V. Regularities of the sorption behavior of actinide ions on mineral colloid particles. Russian Journal of General Chemistry, 2011, vol. 81, no. 9, pp. 2029-2038.

20. Martynov K.V., Konevnik Yu.V., Zakharova E.V. Barrier properties of crystal rocks during radionuclides migration. Radiohimiya, 2017, vol. 59, no. 4, pp. 371-378. In Rus.

21. Kaimin E.P., Grafchikov A.A., Zakharova E.V., Konstantinova L.I. Vzaimodeistvie radionuklidov s tekhnogenno preobrazovannymi porodami [Radionuclides interaction with technogeneous regenerate rocks]. Geoecology, engineering geology, hydrogeology, geocryology, 2008, no. 1, pp. 29-38.

Received: 10 December 2018.

\section{Information about the authors}

Mikhail V. Antonenko, Cand. Sc., deputy chief engineer, Mining and Chemical Combine.

Aleksey V. Leonov, works director, Mining and Chemical Combine.

Evgeny V. Bespala, Cand. Sc., lead engineer, Mining and Chemical Combine.

Dmitry O. Chubreev, head of laboratory, Mining and Chemical Combine.

Yuliya R. Bespala, engineer, Mining and Chemical Combine. 